\title{
Towards a Theory of Digital Media
}

\author{
Abstract \\ This paper puts forward a theory of the role of digital media in social change. It begins by criticizing \\ three theories that currently dominate our understanding of digital media and of media generally; \\ network theory, mediatization theory, and actor-network theory. It also identifies a gap in current \\ communication theory; namely, that digital media mostly do not fit the divide into mass and \\ interpersonal communication. A further problem is that insufficient attention is given to the \\ difference between political communication and popular culture or everyday life. The paper \\ develops an alternative, focusing on four countries that provide a range of relationships between \\ media and society; the United States, Sweden, India and China. In all four countries, despite their \\ differences, digital media, in contrast to traditional broadcast and interpersonal media, have led to a \\ more differentiated media landscape. Greater complexity in political communication nevertheless \\ runs up against the continuing dominance of elite agenda setting. In terms of popular culture, all \\ four countries have experienced a proliferation of media offerings, new forms of information \\ seeking, and greater tetheredness between people. Hence new divides are emerging between more \\ active and variegated as against more passive and restricted media uses. The paper concludes with \\ implications of digital media for understanding media generally: with new digital media, there is now \\ a need to rethink media theory in terms of fundamental debates about how media transform or \\ preserve the social order.
}

\section{Introduction}

Digital media have been responsible for some of the most wide-ranging changes in society over the past quarter century, yet there is little agreement in the social sciences about how these changes should be understood. Part of the reason is increasing disciplinary specialization, with media studies and communication research concentrating on specific areas without a broader analysis of how media contribute to social change. Sociology, on the other hand, has, with a few exceptions that will be discussed, left the study of new media to the discipline of media and communications. Other disciplines, such as political science, tend to concentrate on specific questions such as the role of media in election campaigns or for social movements. The sociology of science and technology, meanwhile, has adopted a stance whereby generalizations across particular contexts of the uses of media technology are deemed impossible. A further problem that currently bedevils theories of media is that theories that were suited to mass media and interpersonal communication are no longer suited for digital media - since new media often have elements of both.

Some brief examples about how 'mass' versus 'interpersonal' misleads for digital media can suffice at this point: first, there is the growth of user-generated content, which goes beyond passive 'audiences' and 'senders versus receivers'. Second, news and other content is often shared among groups on social media rather than on a one-to-one or one-to-many basis. Third, the way that much online information is accessed, such as via Wikipedia, is subject to new gatekeeping mechanisms, especially search engines, that are different from traditional gatekeepers, like professional journalistic norms or control by publishers and other media institutions. At the same time, a theory of digital media needs to take into account that traditional media still often dominate, for example during election campaigns, while simultaneously recognizing the extent to which digital media have displaced and complement traditional media, especially among younger people. One way to address 
this simultaneity of 'old' and 'new' is to talk of 'hybrid' media (Chadwick 2013), which postulates the side-by-side existence of both, in this case in politics. But this does not overcome the need for a theory of digital media, as it leaves open the balance of this 'hybridity'.

The few theories that have tackled the changing media landscape all have shortcomings: Castells' theory of network power (2009) has two main elements; an ontology that all media are best understood as working via networks, and a theory of power whereby power is increasingly concentrated in a few global transnational media conglomerates but that this concentrated power always also generates resistance. Both ideas are flawed since there are countries in which the capitalist imperatives of media conglomerates play a far lesser role, such as China where the partystate primarily controls media, but also Sweden where public media still play a dominant role. Put differently, national 'media systems' (Hallin and Mancini 2004), which can be grouped into regional types, still trump the dynamics of capitalist concentration and provide strong boundaries around how media operate, as well as the bounds within which most popular inputs, for example, shape politics via media, as we shall see.

The second major theory, mediatization theory (Hjarvard 2008), takes these national differences into account, and argues that peoples' relationship to society is increasingly mediated. Yet the theory lacks analytical precision about which particular areas of social life are being mediatized: mediatization is defined as the 'the process whereby society to an increasing degree is submitted to, or becomes dependent on, the media and their logic'; media become 'integrated into the operations of other social institutions' and also 'social institutions in their own right' and 'as a consequence, social interaction - within the institutions, between institutions, and in society at large - take place via the media' (Hjarvard 2008: 113). There is much to recommend this theory, but it is important to distinguish between cultural and political power, or their respective spheres, and how, as we shall see, media operate quite differently within them. Further, while new media add to the mediatization of social life, it is also possible to argue that disintermediation takes place, as when people produce content directly, outside of institutions.

Actor-network theory is more about new technologies than about media, but it has had a wide influence in media studies (for example, Chadwick 2013; Couldry 2012). This theory puts the emphasis either on agency of individuals or of non-humans (in which case there is a kind of backdoor technological determinism, which the theory otherwise rejects). Yet 'agency' cannot account for structures, and the non-human physical environment does not engage in volitional acts. Actornetwork theory also, like other theories of science, technology and social change, has been dominated by the idea science and technology are constructed or shaped by specific local social contexts, thus making it impossible to generalize about the role of media beyond individual contexts of constructedness or shaping. Yet general patterns are essential if theory is to guide research, and structures are essential to uncovering asymmetries of power.

There are other media theories, but these three strands currently dominate. It is important to add, however, that much empirical media or communications research operates with theories of the middle range. These include agenda setting, gatekeeping, framing, uses and gratifications, and rational choice or collective action. These theories all operate on the presupposition that research can operate without an overall or macro- theory of social change, except perhaps that they implicitly 
take the stance that the main aim of research should be to counteract excessive control or bias by some groups at the expense of others. In doing so, they presume a pluralist view or a theory of ideologies competing in the marketplace of ideas (Neuman 2016). The notion that ideas or ideologies compete in the media is an important one. However, with few exceptions (some key examples will be discussed), this research programme focuses on individual media, making it impossible to understand, for example, how agenda-setting works across traditional and new digital media. Moreover, this type of research typically focuses on media on the national level and for particular domains and periods. Yet there may be important lessons from comparisons (Esser and Pfetsch 2004), from longer-term trajectories, and again, from analysing the range of media. And it will be argued that it is necessary to identify structural constraints to the competition of ideas or ideologies - rather than having an open-ended market, at least in the political realm.

The alternative put forward here rests on three arguments: first, national differences matter for the implications of digital media just as they did for traditional media. This entails that 'media systems' theory (Hallin and Mancini 2004) is an essential starting point, although it will also be modified. Second, while new digital media add to and complement traditional media, old and new media must be encompassed within a single framework that enables an understanding of how control of the political agenda, for example, is shaped across media. As we shall see, the ideas of a limited attention space and of a dominant agenda across media are useful here. Third, this limited attention space, and also limits on individuals' connectedness to each other and to information, operate differently in relation to political communication as against popular culture.

Apart from these arguments, it will be assumed that validity of theories of media must be based on evidence about how new technologies are integrated into everyday life. This 'bottom-up' approach to the role of media is the strength of domestication theory (Haddon 2011) and also of holistic views of how media perpetuate or overcome asymmetries of power. Media should be gauged by how they are used, and with what effect for social change, which overcomes the disciplinary divides mentioned earlier. Understanding everyday life must not exclude macro- dynamics, however, and particularly politics and wider longer-term and cumulative changes and discontinuities - but also similarities - across societies. These gaps will be overcome here by making comparisons across four countries, both on the levels of everyday life and macro-changes, and contrasting what has changed as between traditional and new digital media. This is the contrast to which can now turn.

Before we do so, it is useful to sketch the remainder of the paper: Once a contrast has been made between traditional and new digital media, the paper will give a number of examples of theoretical approaches which capture how digital media go beyond traditional media. In relation to these examples, we will see that an increasing mediation (or mediatization) of everyday life applies to all of them, but that it is necessary to make arguments about a limited attention space in relation to politics, as against the non-zero sum expansion of digital media in popular culture, including access to information and socializing online. Examples will be given to illustrate these arguments; that is all that can be done within the scope of a paper (the paper is part of a larger book-length project which spells out the argument in detail and with more systematic evidence). We shall also see that there are greater and lesser divides between information- and connection-rich and-poor within and between countries. The paper concludes with the argument that theories of digital media must 
recognize asymmetries in media power - while at the same time putting media in their place in terms of whether they merely reflect or challenge these asymmetries.

\section{New Media and Traditional Media}

How do new media that enable self-publication, sharing in networks, and information seeking depart from traditional media? The main difference is that unlike broadcast and interpersonal media, new media enable a more differentiated and fine-grained push of media towards audiences on the one hand, and a scaled up and more active media engagement by people on the other. Altogether, the media landscape has become more complex, both from the top down, in terms of offerings, and from the bottom up, in terms of how media are consumed. However, even if new media add to and complement traditional ones, the proliferation of media is still subject to how the sum total of mediated inputs contribute to political change on one side, and to changes in popular culture, which includes socializing and accessing information, on the other. This way of conceptualizing new media can now be spelled out in greater detail for four countries which have been selected because they represent a most dissimilar comparative design in terms of advanced democracies and of models or paths for developing countries. We can start with politics.

Political rule in contemporary societies is legitimated by citizens' inputs, and these inputs are almost entirely mediated nowadays. As Luhmann put it, in a claim that is only slightly exaggerated because it does not take into face-to-face interaction, 'what we know about our society, or indeed about the world in which we live, we know through the mass media (2000:1). The exceptions to this type of legitimacy among the countries considered here are China, where these inputs are constrained by the single party state, and India, where this input is manipulated by the collusion between political elites and the economic elites that control the media. This leads immediately to two further points: the first is that mediated political inputs in the US and in Sweden, even if some would argue that they are skewed towards powerful actors, originate in society and are translated into political agendas via autonomous media institutions. In India and China, media are, for different reasons in each case, less autonomous. From a comparative perspective, the degree of autonomy of media institutions is thus an essential feature in the analysis of media and social change, as Hallin and Mancini (2004) have argued. The implication is that how new media add to traditional ones must be combined in a single analysis of political inputs against the background of different media systems.

The second point is that in India and China, new media, howsoever they are controlled by the partystate (China) or dominated by elites (India), are nevertheless less controlled than traditional media. This point is often made by cyberutopians who argue that digital media may lead to greater democracy. Yet this argument needs to be put in its place by pointing out that everywhere, it is the sum total of inputs into political rule which determines the political role of the media, and these are constrained by how much attention ruling elites pay to them. Put differently, media, old and new, are only an autonomous subsystem within the political sphere, and hence too the responsiveness of the political apparatus and of politically relevant elites to old and new media determines the extent to which inputs are taken into account. The media system is autonomous inasmuch as it is not controlled by elites or citizens or economic forces (with the provisos mentioned), but it is only a subsystem because media do not themselves change the direction of the political system; political elites and citizens do. 
As this idea is a departure from traditional media theories, it deserves highlighting: traditional theories of the media and politics are based on the implicit assumption that the space of politics is open-ended. However, gatekeeping and agenda-setting theories, at least implicitly, acknowledge that the political attention space (Neuman 2016) or the visibility (Thompson 1995) or the power of the public to influence politics via media is limited. This implicit assumption is made explicit here, with the idea that the media subsystem feeds into - not society as a whole or an open marketplace but into a distinct sphere of political power (Mann 2013) or into the political order (removed for review 2013). In other words, the effect of media on politics as against other forms of power can be separated; in politics, media operate on the basis of a different logic from how media operate in other powers or orders: within a single political order, media provide an input where only a few worldviews or ideologies dominate across old and new media.

The idea that only a few, typically less than half a dozen, competing positions dominate the attention space, has been conceptualized with the 'law of small numbers' (Collins 1998: 37-46). It is easy to see that it applies to the realm of politics, where during election campaigns and periods in office, politicians and parties and citizens focus on a few dominant issues (Gans' idea (2004) of the 'news hole' also captures this idea of a limited attention space and the law of small numbers). These issues come and go, if we consider, for example, how immigration in the US and Sweden currently dominate the political agenda as against how climate change has faded from view, or how poor air quality and corruption have recently come to dominate politics in India and China, issues that were absent or far less important before. Hence how the media subsystem feeds into political power or into the political order can be regarded as a whole; there is a structural constraint or a hierarchy whereby more powerful ideologies or worldviews achieve most visibility across the attention space, an idea which deserves further elaboration.

The media constitute the single most important input into the political process, translating citizen inputs - which include public opinion and social movements and other interests in civil society - into how elites govern. At the same time, these inputs, and how elites respond to them, do not take place in an open-ended space: certain political worldviews or ideologies dominate, and they set the parameters for how decisions are made, while others are left out or have little visibility. This idea of inputs partly draws on Luhmann's (2000) functionalism, except that it allows for conflict over which political ideas dominate: there are struggles for visibility (Thompson 1995) such that political elites respond principally to the inputs which will keep them in power or preserve their legitimacy. The dominant political ideas, or worldviews, consisting of a few agenda items, shift, but across all media, certain inputs dominate. Within this closed political space, there is limited attention within the media subsystem, a hierarchy of mediated inputs whereby some shape the agenda more than others. Gatekeeping mechanisms and agenda setting play a role here: digital media, even where they are less gatekept or enable agendas from new sources, can extend mediated input, but this input must nevertheless find room within a crowded space. This point will be illustrated with examples shortly.

Before we turn these examples, it is useful to contrast the mediated inputs into politics and their zero sum struggle for visibility with the role of media in popular culture. Here too certain types of content dominate, but this dominance is more diffuse: different audiences overlap and intersect in plural 'taste cultures', as Gans (1999) argued. Gans further argued that as long as there is scope for 
diversity, or if pluralism of content can be preserved and strengthened, the media would play a positive role in society. In this sense, the idea of a diverse or open-ended 'marketplace' is appropriate. Digital media, as we shall see, extend the offerings of traditional media, though there also new forms of concentrations of digital content, and in this sense support this diversity. The mediated cultural order includes not just leisure or 'high' and 'popular' culture, however, but all symbolic media outside of politics. This includes information seeking and sociability in everyday life, and these two activities deserve further conceptualization.

Information seeking has expanded with online media, a point that will be elaborated shortly. Most of this information is for leisure and consumption, as we shall see, but there is one type of information where access should not just be diverse, but where access to reliable information may be indispensable to leading a full life; a means for enhancing 'capabilities' (Sen 2009). Savolainen (2008) has labelled this 'serious' information: examples include health, educational materials and materials relating to personal welfare such as jobs. Seeking information online has rapidly become a primary activity in the use of the internet, second only to communicating, and certain new technologies such as search engines and social media have become important gatekeepers here.

Finally, there has been an increase in online socializing, and here too the role of media, especially social media, has expanded. Interpersonal communication has 'scaled up' with social media, as Miller et al (2016) argue, yet here too (as with culture, including information seeking) there is a diffuse limit in terms of the hours spent and the number of people one can be tethered or connected to. Or again, despite the proliferation of ties, studies have shown that the number of people we communicate with on social media and mobile phone come up against barriers (Dunbar 2012, Ling et al 2014). Still, social media and mobile phones or smartphones extend and intensify the reach of traditional media for sociability.

These together constitute the main elements of the cultural order, but instead of a zero sum game of dominant visibility, in the realm of culture, only peoples' much more diffuse and open-ended attention constitutes an outer limit; otherwise, digital media extend and complement traditional media. In the case of both, the political and the cultural order, old and new media can be regarded as a totality, and the limits of the attention space are the extent to which media are used - engaged with or consumed - in everyday life, and have different implications in the two orders. These arguments and theoretical ideas can now be illustrated with concrete examples. Again, in a single paper, it is not possible to do more. In the conclusion, it will be seen that these ideas add up to a new way of understanding how digital media go beyond traditional media, adding to and complementing them.

\section{Online Information Seeking}

As already mentioned, information seeking, now online, has become a more prominent activity in everyday life and fits neither mass nor interpersonal communication theory. It is in any event a departure from traditional media, which were, in terms of seeking information, constrained by their physical availability. One approach here might be to argue, as Castells does (2009), that the main change is 'self-selection', whereby people choose the online material that best fits their needs. This overlooks that there are new gatekeepers even when information is chosen rather than passively received, as with search engines or social media feeds or other constraints on the visibility or 
accessibility of web pages. However, it is true that, apart from these gatekeepers, some online resources both extend existing sources and are openly accessible.

One example here is Wikipedia, which is the only non-commercial website among the top ten for many languages and countries (http://www.alexa.com/topsites). Wikipedia, like other openly available online information sources, extends mediatization, since it has become a widely used resource for a range of topics for many internet users. Yet there are also new gatekeepers: Waller finds that in Australia, 93\% of clicks on Wikipedia come via Google, and Google is the dominant search engine in Australia, with more than 90\% share (Waller 2011) of search engine uses (Australia is discussed here rather than the four main countries in this paper because this is the country for which the most detailed analysis of Wikipedia uses and online information seeking is available). This new information source also creates new divides: some Australians do not have access to the internet or the digital skills to use it if they have access.

Moreover, while Wikipedia provides a source which is widely regarded as reliable for serious matters (though this will continue to be a matter of debate), most of the content that is sought via the dominant search engine Google concerns popular culture and the like which arguably fall into the category of leisure rather than capability enhancing (Waller 2011). But this is also true of search engine uses generally, which are mainly used for leisure and consumer related information seeking around the world (Segev and Ahituv 2010). Thus even if online information seeking, in this case using Wikipedia as a resource, is mainly for topics that are not serious, it is nevertheless easy to see that some categories of information (such as for health, science, and civic topics) can play an important role in peoples' lives, even if they are far less common. Traditional media and communication theories do not address the general role of information seeking in everyday life, which has fallen to information scientists (Rieh 2004; Savolainen 2008; Aspray and Hayes 2011). Yet information science, in turn, fails to consider the broader implications of online resources in everyday life outside of individual contexts or particular groups.

Hence the need to include this important activity - again, recently much expanded - in the wider theory of digital media offered here, as follows: online information sources (here, with the example of Wikipedia) extend the reach and depth of traditional media. The Web as an information source is distinct from the information sources of traditional mass and interpersonal media, but it is also subject to similar constraints as other digital media, competing with them for attention: for example, even if Wikipedia is often among the top results when using a search engine, there are many other online and offline sources that could be used (with and without the use of search engines). Further, online information sources exemplify the overall argument that digital media push content towards users in a more targeted way, as when search results prioritize finding Wikipedia articles (or other information) for particular users because the search algorithm has been tailored that way (Pariser 2011). Finally, these new online sources add to and complement others, but media systems also shape them: in China, the Chinese language version of Wikipedia has been blocked for certain periods, and a different online encyclopaedia, Baidu Baike, with content controlled by the company Baidu which is in turn influenced by the government, is dominant on the mainland (Liao 2009).

\section{Mobile Phones and Politics}


New media complement and extend traditional information sources. Do they also reshape political communication? Here we can take an example comes from India, where internet penetration has been low but the spread of mobile phones has surged in recent years. In this case, mobile phones have extended the role of new digital technologies, playing a crucial role in politics, as documented in detail by Jeffrey and Doron (2013: 143-164) during the election in 2007 of Mayawati as chief minister of Uttar Pradesh (U.P.), which is India's by far most populous state. At the time, mobile phones had just broken through to reach a sizable part of the population of the state, 31 million out of a population of $\mathbf{2 0 0}$ million. As Jeffrey and Doron note, mobile phone ownership was heavily skewed towards the middle class, but it was also widespread among the Dalit civil servants working in the government's Post Office and Communications departments. Mayawati's party, the Bahujan Samaj Party (BSP), was based on a Dalit (formerly known as untouchables) political organization, and she herself came from a humble Dalit background. Dalits, $20 \%$ of U.P.'s population, continue to be widely disenfranchised, despite laws against this, for example by not being allowed in certain public spaces and because they are intimidated by landowners. Jeffrey and Doron also note that the 'major newspapers and television channels', controlled by Hindu elites, were 'disdainful of the BSP and often hostile to Dalit-oriented policies (2013: 154).

Jeffrey and Doron argue that the use of mobile phones was a necessary even if not a sufficient factor in Mayawati's victory. The election was won by combining a top-down and a bottom-up strategy for mobilizing voters at the level of election booths: party activists were coordinated via voice and textmessage at organizations consisting of both Dalits and Brahmins ( $10 \%$ of the population, and allied on this occasion with Dalits) around thousands of polling stations, encouraging them to get voters, and especially sympathetic women, registered and out to vote, preparing visits by party leaders, disseminating their messages, and making sure that they knew the correct symbol to push on the voting machine or ballot (in India, with high illiteracy, each party has a symbol, an elephant in the case of the BSP). Jeffrey and Doron draw analogies here with the election campaign that took President Obama to power in 2008, where a similar person-to-person ground-level campaign was fought (see Nielsen 2012; Bimber 2014). They suggest that this person-to-person strategy was especially important in U.P. so as to establish trust between Dalits and Brahmins and persuade them that the BSP represented their common interest.

Another key element was that phones were used to report wrongdoing and intimidation to the Election Commission, including taking pictures of voting irregularities on mobile phones. It must be added that, at the time, the other parties were lacking in this mobile-phone based mobilization. Since that time, Jeffrey and Doron say, other parties have begun to do so, and so the window of advantage of the BSP's innovative mobile phone use has gone. Still, on this occasion, they argue that mobile phones played a crucial role, saying that it constituted a 'disruption' in Indian politics which 'bypassed mainstream media' (2013: 163). Mobile phones worked differently from other media and from the internet in this case: enabling two way connections with the expectation that relations between party officials and activists would be maintained, involving one-to-one conversations rather than mass-mailings, and making 'widespread frequent communication possible and involved people who would rather speak and listen than read and write'(2013: 154). In short, like the large populist rallies that are characteristic of Indian politics, this use of technology fits well with mobilizing a part of the population using cheap and cheap-to-use devices via the right modality (Arnold 2013; Donner 2015). This example shows that digital media, even of the low tech variety and where most of the 
population is not online, extends mediatization, although it remains to be seen if there are wider implications for bottom-up political mobilization in India. And again, digital technologies do not fit straightforwardly into the 'mass' or 'interpersonal' categories here: they are closer to interpersonal media, but the ability to send a text to large numbers of recipients in this case went beyond traditional uses of the phone, as did having communication devices that were mobile and could takes pictures.

\section{Agenda-Setting in Traditional and Digital Media}

The question of how new media go beyond traditional media has also been addressed with agendasetting theory, which is among the foremost theories of the media in politics. Agenda-setting is about the topics that are foregrounded by the media; not what media make people think, but what it makes them think about, in the well-known phrase. Agenda-setting theory has mostly been used for specific media or topics or events (McCombs 2014), but it could potentially overcome the study of individual media if agendas could be investigated across major media and longitudinally, which has been rare. If, moreover, the agendas concerned are the ones most prominent in the media and also important in the minds of citizens, then it can be assumed that they fit the notion that the attention space is limited; certain agendas dominate and only certain topics become powerful enough to translate into political change. Bimber has suggested that in the US, 'competition for political attention [is] growing more aggressive, against a background of largely unchanged habits of political knowledge and learning'(2003: 230), and it is easy to see that, with digital media, competition has become even more intense. What remains also largely unchanged, however, is that political elites are influenced by how public opinion and citizen interests are represented in the media, and also the need to translate these agendas into policy, prioritizing some over others.

The idea of a limited attention space has been put forward in the US context by Neuman (2016), and together with colleagues (Neuman, Guggenheim, Mo Jang and Bae, 2014), he examined agendasetting in traditional news media compared with online media by reference to data from newspapers and television compared with Twitter, blogs, and discussion forums for the year 2012. They took the 'most important issues facing the country' which Americans have been surveyed about for several decades, and which are grouped into certain rubrics, and analysed how frequently the keywords associated with these issues appeared in traditional and new media. Then they asked 'who sets the agenda', or whether issues appear first in traditional and then in new media or vice versa, as well as the difference between two. Among their findings, concerning the latter question: 'Social media are more responsive to public order and social issues and less responsive to the abstractions of economics and foreign affairs'(2014: 7). This finding has important implications since it suggests that what journalists are interested in differs from what people are interested in when they generate or can select content themselves (see also Boczkowski \& Mitchelstein 2013).

The study is rare in testing an existing theory in media and communications - agenda-setting - for traditional and new media, with the interesting result that the two are different, even if, as the authors point out, it will be increasingly difficult to tell them apart as there is increasing traffic between them. At the same time, monitoring public attitudes via social media has become, as Bimber among others has noted (2014), a routine input into the political process. And while this monitoring and targeting applies across media systems, again, there is a difference in how this 
process is used in China, where the government can use new media to control the population (Stockmann 2013; forthcoming). In the US, in contrast, the fact that agenda-setting may be shaped more by the public inputs into the political process, and the selection of media content is likely to make media more audience-driven, and in this sense the media may become less autonomous, if for quite different reasons than in China.

\section{Circumventing Traditional Gatekeepers in Sweden}

Another major communication theory is gatekeeping, though it has not yet been applied systematically to the role of new media in politics (Barzilai Nahon 2012). One question that has been debated whether (Larsson 2015) smaller or less well-known political actors can achieve a disproportionally larger visibility or influence on social media than in traditional media? A good test case here are the Sweden Democrats, a populist right wing party with an anti-immigration agenda that has recently risen to prominence in Sweden. This party also has an extensive online presence, especially on social media like Facebook and via alternative newspapers.

Indeed, Larsson, for example, found a 'tendency for ideologically marginalized parties to gain more traction in novel media spheres than in the coverage by curated by established media actors' (2015: 12) during the 2014 Swedish election, which also benefitted other smaller parties such as the Feminist Initiative and the Pirate Party. However, unlike these two parties, the Sweden Democrats were no longer marginal by 2014, gaining the third largest share of votes (they had already passed the $5 \%$ threshold of votes to gain seats in Parliament in 2010, unlike the other two). Some polls have subsequently, in the wake of the migrant crisis, put them ahead of all other parties (https://yougov.se/news/2015/08/20/sd-ar-sveriges-storsta-parti/), even though they have been blocked by an alliance of the conservative party (Moderaterna) and the Social Democrat party from having much influence in government. At the same time, the Sweden Democrats, whose popularity predates the recent migrant crisis (the party was founded in 1988) have a history of being ignored by other parties and in the mainstream media (Hellstroem, Nilsson and Stoltz 2012).

This disproportionate attention in new media beyond traditional media has to be put into a larger context: More than half of Swedes aged 26-55 use the internet for news on a daily basis, and those under 46 regard the internet as the most important source of news - with TV far behind (Findahl 2014: 65, 66). Among television audiences, the public service channels continue to have a large (36\% in 2007) audience share (Aalberg, Strabac, Brekken 2012: 18). Compared to the US, which is television-centric, Sweden is a more newspaper-centric society (Norris 2000: 85; Norris and Inglehart 2009: 58-9, Aalberg and Curran 2012). Thus the elite political agenda in Sweden is shaped mainly by the two main daily 'quality' newspapers which support the right and the left parties, and by public television news.

While traditional media continue to play this dominant role, younger Swedes in particular are shifting towards digital media at the expense of traditional media. Westlund and Weibull (2013) have documented this transformation by using longitudinal surveys and dividing them into different media generations (those growing up before World War 2, the post-war baby boomers, 'Generation $\mathrm{X}^{\prime}$, and the recent generation growing up with digital technologies) as well as changes in media use over the life course of individuals. For these groups, they have analysed changes in news consumption between 1986 and 2011 across all media. What they show is that although the earlier 
generations stick to public service media, there is a shift away from public service to commercial TV and radio among the younger generations. The same applies to print newspapers, where the younger generations have shifted to digital versions. Recently there has also been a shift away from paid-for quality newspapers to free ones (Metro) and to mobile news consumption. Among 16-29 year olds, Weibull and Wadbring (2014: 327) find that a higher percentage reads newspapers on mobile devices than in any other format, digital or print.

Thus while newspapers and public service media still dominate among the population as a whole, this is not the case among the younger generation and those at an earlier stage in the life course. Westlund and Weibull point out that this is not a question of complete displacement: the earlier generations add to their repertoire of news consumption with commercial broadcasters and online versions. Nevertheless, there is an unmistakeable shift away from print newspapers and public service news to more diversified sources of news and online news among the younger generations and for those at an earlier stage in life. And if this younger generation especially is influenced more by new media, where parties like the Sweden Democrats are more visible, the two shifts - whereby certain parties circumvent traditional gatekeepers and increase their share in the online attention space - are bound to reinforce each other over time. In the US, as we have seen, online media reshape the focus of the news agenda; in Sweden, they also reshape which political forces are visible in the online attention space.

\section{Control and Resistance in China}

A different circumvention of gatekeeping can be found in China, where the elites of the party-state exercise direct control over media and the political agenda (Brady 2008). This control and how it is partially evaded is the main context for understanding more extensive mediatization in China. Whereas in democracies, media have become an autonomous institution, this does not apply to authoritarian regimes like China, where media remain largely de-differentiated for political purposes, and so do not provide an independent input, even if party elites are partially responsive to media. However, we also encounter a paradox: while the degree of pluralism in Chinese society, or input from people, is low, the degree of engagement via media for political purposes, within the limits set by the state, is comparatively high, particularly at a local level. So while the central government maintains tight control over media at the national level, it also uses media to put pressure on local government and also monitors and measures public opinion, particularly concerning societal issues (Stockmann forthcoming). It is also well-known that Chinese citizens, especially younger urban ones, regard news disseminated via public television and official newspapers as state propaganda and less revealing than commercial and especially digital media.

The disproportionately powerful role of digital media compared with traditional media in China therefore arises from the fact that it is precisely in a repressive society that they provide a potential outlet for alternative political views. This does not mean there is widespread discontent with the government, the 'myth of the social volcano' (Whyte 2010). Nor do these alternative views predominantly favour democracy or liberalization of the economy: populist nationalism is also disproportionately strongly represented online (Leibold 2010), as in Sweden. Nevertheless, having loosened the grip of state controlled media and allowed varying degrees of online expression, the regime faces the dilemma of how much control to exercise over digital media, which are less easy to control than traditional media. Stockmann (2013) has argued that the Chinese government is able to 
use the increasing the increasing commercialism among traditional media to exercise greater control because it is able to gauge public opinion better even while citizens trust market-oriented media more (2013). This argument can also be applied to digital media (Stockmann forthcoming), though digital media require greater control (it can be mentioned here that in China, media require at least $51 \%$ state ownership; in India, they require at least 51\% domestic ownership).

An important context here is the intensive level of internet usage: according to Bolsover, Dutton, Law and Dutta (2014: 126), internet technology 'has become an integral part, not just of the nation's economy, but of the everyday lives of the majority of Chinese internet users in a way that surpasses that of any of the nations that we surveyed', which included the United States. The growth of the internet and proliferation of social media has led a number of China scholars to argue that the internet is the most vibrant arena for protest against the regime (Yang 2009). In this case, what we see is that even if digital media extend the role of media, input from society is a double-edged sword in authoritarian societies, since the regime can use this input to its own ends, even as it needs to adapt to the increasing role of media that require new forms of gatekeeping and control.

\section{Densifying Personal Networks}

In everyday life, perhaps the most dramatic change that has been brought by digital media is that the frequency and density of personal connections has intensified and become more complex, as have the modalities through which the connections are pursued. As already mentioned, this does not mean that the overall number of personal connections has increased (Fischer 1992; Dunbar 2012). Still, in all the countries examined here, socializing, or 'sociability', has scaled up, at least insofar as people have more frequent multimodal connections (Miller et al 2016 for India and China, reference removed for review (2014) for the US and Sweden). 'Scaling up' is not quite right since people do not have connections with more far-flung networks: as Ling et al (2014) have shown, our daily networks of the number of people we connect with is rather small: they analyzed mobile call records in Norway for a three month period from the dominant mobile operator in the country and found that most connections are with a small group of people that are close by: 'the mobile phone...is used in the maintenance of everyday routines with a relatively limited number of people in a relatively limited physical sphere of action...the stronger is our tie...the closer they are likely to be geographically' (2014: 288). However, it is clear that people share more content with others in small groups via social media (Kümpel, Karnowski \& Keyling 2015). In this way it is becoming increasingly difficult to disentangle sociability from broader effects on culture and politics since people often share cultural and political content on social media. In any event, the increasing mediatization of everyday sociability at a minimum requires more management of interpersonal relations (Nippert-Eng 2010) and monitoring others.

As for broader changes, Miller et al (2016: 145-47) argue that the political implications of social media are largely conservative insofar as the content of social media upholds local norms and mainly serves to enhance the status and reputation of those posting the content (recall the finding above by Neuman et al [2014] that shared content is more 'local'). While this may be true in terms of content, a different way to examine the relation between sociability and politics on social media is to ask whether those who are ideologically close together also 'flock together' online? Bakshy, Messing and Adamic (2015) investigated this question for more than 10 million American Facebook users, and found that Facebook friends are ideologically quite diverse, which is partly because their ties reflect 
offline networks such as family, school and work - in contrast with Twitter users who share common interests or topics but not necessarily offline ties, and who are therefore more ideologically polarized (Conover et at 2011). The larger context here is that $60 \%$ of Americans use Facebook, $73 \%$ of American Facebook users make frequent 'status updates', and $66 \%$ use it for civic or political activity (Hampton et al 2011, Rainie et al 2012).

These findings suggest that different social media have come to reflect different interests, groups and ideologies. At the same time, Facebook is only one of several social networking sites, even if it is the dominant one in the US and worldwide. In China, it is almost non-existent because the government has banned it, even if other social media uses, including for political expression, are widespread in China (Bolsover, Dutton, Law and Dutta 2014). These changes are not easy to summarize, since the extent of cultural and political participation and engagement varies so much across the four countries examined here (removed for review). What is clear is that there continues to be an increase in the depth and breadth of social media uses across all social strata, even if major divides persist. The implication is that mediatization theory applies to all four countries, also for sociability, where interpersonal relations are densifying and people are increasingly tethered to each other in addition to being more tethered to information - as we saw earlier.

\section{Conclusion}

Ultimately, the ground on which the shift from traditional to digital media must be assessed are the everyday uses of media, including for sociability, on the one hand, and for politics, in the macroshifts in media systems and control over dominant ideas within a limited attention space across both traditional and digital media on the other. But where does the most telling evidence of changing media uses come from for the kind of comparative analysis presented here? There are comparative surveys of media (Norriss and Inglehart 2009; World Internet Project http://worldinternetproject.net/), and also detailed ethnographic studies (Miller et al. 2016). An obvious problem that has emerged in the course of this analysis is that some user groups (typically young, urban, affluent - though not always: recall Mayawati's election) are often at the forefront of change. A second problem is the disconnect between changing everyday user practices and macrochanges in politics: the two may connected, as with news sharing on social media, but it is still only when there are tangible connections, as when there are new popular movements or shifts in public opinion, and these mesh with the emergence of new political forces that can take advantage of new media (circumventing gatekeeping, shifting the agenda, mobilizing disadvantaged groups) - only then can we identify how and where digital media make a difference, even if the difference is incremental. However, the problem of recognizing various early and limited changes may seem more insuperable than it appears: political elites are responsive to the media subsystem as a whole, and even if traditional media still dominate the attention space, digital media add to the inputs of traditional media as long as it can be documented that they resonate with wider social forces, as has been done here.

This paper has argued that there has been an increasing interpenetration between media and two areas of social life; politics and culture. Digital media have extended the reach of media into everyday life: in culture, online information seeking has become a more integral part of daily life; information content has become more variegated; and connectedness with others has become more 
frequent (sociability). The main change is that a greater portion of disposable time is spent online, but this also points to the limits of this change: time, attention, and usefulness of content limit the extent to which we are tethered to others and to information. In politics, communication between people and elites has become denser, more intensive, and needs to be managed more actively by both sides (which may also lead some citizens to avoid news more, among other things, Prior 2007). The limit in this case are the dominant mediated agendas and how they shape the input from society into the political process.

These are the two main areas where new digital media have changed social life (the other, production of goods and services and work, are beyond the scope of this paper). The transformations are best captured by a perspective that gauges how new media technologies become embedded in everyday uses, and how digital media have added to and complement traditional media. Mediatization theory captures this change well, suggesting an increasing penetration of society by media. But this theory is too all-encompassing since there are no bounds to this process (which have been theorized here with limited attention space, gatekeeping, and dominant agendas) and no distinction between how mediatization works differently in the realms of politics and culture. The idea put forward here has been that there are two more specific forms of mediatization of politics and culture, with dominant agendas in a limited attention space in the one case and a plural and more diffuse taste cultures on the other, and additional information sources and more tethered sociability.

Thus two patterns account for change in politics and culture across four countries: for politics, at the macro- level, there has been a shift towards deeper and broader and more managed mediated relations. The aggregate effect of this shift is hard to discern because it has only been possible to give examples: has there been a general increase in the responsiveness of political elites to people during the decades in which digital media have become widespread? Bimber has argued that such a change has taken place in the US, but with marginal effects at best (2003). But broader inputs or inputs which make parts of the population more visible vary with media systems; as with the low tech mobilization for Mayawati's election, or the Chinese state's adaptation to social media inputs, or how parties and traditional media have kept online right wing populism at bay in Sweden, or how the agendas of publics on social media depart from the agendas in traditional media in the US. These are ongoing changes, and perhaps the lasting effect of a more mediated political environment will only become evident if more popular inputs and greater responsiveness intensify and new political directions emerge. Put differently, it will be only possible to confirm a transformation due to new media if new forces from below (the uses of digital media) and from above (visibility for new parties) combine such that new inputs constitute an expanded media system. Such a macro-shift may only be discernible with hindsight, but it would be remiss not to notice that steps towards such changes are already under way.

For culture, it is clear that increased mediatization has expanded cultural offerings, and even if divides persist between different taste cultures, there are important implications when these divides concern access to serious information. There has also been a shift towards more extensive uses of media for connectedness, intensifying interpersonal relations and information sharing. This is a general shift in ways of life, and it is possible to adopt a relativist position towards taste cultures as long as they are diverse and used for leisure. Where access to others and to serious information 
enhances peoples' capabilities (or fails to do so), however, it is important take stock of where divides persist, or where gaps between the information have-more and the information have-less (Qiu 2009; Donner 2015) may be increasing, even if overall access continues to expand. In this context it is important to note that the most important divide which also applies to politics, and which separates India and China from the US and Sweden, is that while there is widespread access to digital media by means of different devices in Sweden and the US, in China and India the majority access the internet via smartphones, which Napoli and Obar argue (2015) has far more limited functionality than PCbased internet access. The more passive smartphone use of digital media, they argue, is resulting in a new 'mobile internet underclass'.

This argument brings us back to the realm of politics, where digital media extend the reach and depth of the media subsystem which links elites and citizens. But how it does so depends on the media system as a whole: traditional media hold sway, and so does the party in China and powerful elites in India. Digital media go beyond traditional media, but citizens are forced to stay within bounds in China even as vibrant civil societies and popular forces are given additional scope in all four countries. In Sweden, public broadcasting counteracts these forces, and in the US so does a highly-market oriented and fragmented media landscape. Howsoever digital media become more widespread and powerful, it is only when we recognize their limits that we can also recognize the main patterns whereby they have already shifted the ground.

\section{References}

Aalberg, Toril and Curran, James. 2012. Conclusion, in Aalberg, Toril and Curran, James (eds), How Media Inform Democracy: A Comparative Approach. New York: Routledge, pp. 189-200.

Arnold, D. (2013). Everyday Technology: Machines and the Making of India's Modernity. Chicago: University of Chicago Press.

Aspray, W. \& Hayes, B. (eds.) (2011). Everyday Information: the Evolution of Information Seeking in America. Cambridge MA: MIT Press.

Author. 2007. Removed for review.

Author. 2013. Removed for review.

Author 2014. Removed for review.

Bakshy, E., Messing, S., \& Adamic, L. A. (2015). Exposure to ideologically diverse news and opinion on Facebook. Science, 348(6239), 1130-1132.

Barzilai-Nahon, Karine. 2012. Toward a theory of network gatekeeping: A framework for exploring information control. Journal of the American Society for Information Science and Technology, 59:1493-1512. 
Bimber, B. (2003). Information and American Democracy. Cambridge: Cambridge University Press.

Bimber, B. ( 2014.) Digital Media in the Obama Campaigns of 2008 and 2012: Adaptation to the Personalized Political Communication Environment, Journal of Information Technology \& Politics, $11: 2,130-150$

Boczkowski, P. \& Mitchelstein, E. (2013). The news gap: When the information preferences of the media and the public diverge. Cambridge, MA: MIT Press.

Bolsover, G.; Dutton, W.; Law, G. \& Dutta, S. (2014). 'China and the US in the New Internet World: A Comparative Perspective', in Mark Graham and William Dutton (eds), Society and the Internet. How Networks of Information and Communication are Changing our Lives. Oxford: Oxford University Press, pp.117-34.

Brady, A. M. (2009). Marketing dictatorship: Propaganda and thought work in contemporary China. Lanham MD: Rowman \& Littlefield Publishers.

Castells, M. (2009). Communication Power. Oxford: Oxford University Press.

Chadwick, A. (2013). The Hybrid Media System: Politics and Power. New York: Oxford University Press.

Collins, R. (2009). The Sociology of Philosophies. Cambridge MA: Harvard University Press.

Conover, M., Ratkiewicz, J., Francisco, M. R., Gonçalves, B., Menczer, F., \& Flammini, A. (2011). Political Polarization on Twitter. ICWSM, 133, 89-96.

Couldry, N. (2012). Media, society, world: Social theory and digital media practice. Cambridge: Polity Press.

Curran, J.; lyengar, S.; Brink Lund A. and Salovaara-Moring, I. (2009). Media System, Public Knowledge and Democracy: A Comparative Study, European Journal of Communication vol. 24(1): 526.

Donner, J. 2015. After Access: Inclusion, Development, and a More Mobile Internet. Cambridge: MIT Press.

Doron, A. and Jeffrey, R. (2013). The Great Indian Phone Book: How the Mass Mobile Changes Business, Politics and Daily Life. Harvard: Harvard University Press.

Dunbar, R. (2012). Social cognition on the Internet: testing constraints on social network size. Philosophical Transactions of the Royal Society of London B: Biological Sciences, 367(1599), 21922201. 
Esser, F., \& Pfetsch, B. (2004). Comparing political communication: Theories, cases, and challenges. Cambridge: Cambridge University Press.

Findahl, O, \& Davidsson, P. (2015). Svenskarna och Internet, available at https://www.iis.se/docs/Svenskarna och internet 2015.pdf

Fischer, C. (1992). America Calling: A Social History of the Telephone to 1940. Berkeley and Los Angeles: University of California Press.

Gans, H. (1999). Popular culture and high culture: An analysis and evaluation of taste. New York: Basic Books.

Gans, H. (2004). Deciding What's News: A Study of CBS Evening News, NBC Nightly News, Newsweek, and Time. Evanston IL: Northwestern University Press.

Haddon, L. (2011). Domestication analysis, objects of study, and the centrality of technologies in everyday life. Canadian Journal of Communication 36(2): 311-23.

Hallin, D. \& Mancini, P. (2004). Comparing Media Systems: Three Models of Media and Politics. Cambridge: Cambridge University Press.

Hampton, K., Goulet, L. S., Rainie, L., \& Purcell, K. (2011). Social networking sites and our lives. http://www.pewinternet.org/2011/06/16/social-networking-sites-and-our-lives/

Hellström, A., Nilsson, T., \& Stoltz, P. (2012). Nationalism vs. nationalism: The challenge of the Sweden Democrats in the Swedish public debate. Government and Opposition, 47(2), 186-205.

Hjarvard, S. (2008). The Mediatization of Society: A Theory of the Media as Agents of Social and Cultural Change. Nordicom Review, 29(2): 105-34.

Kümpel, A. S., Karnowski, V., \& Keyling, T. (2015). News Sharing in Social Media: A Review of Current Research on News Sharing Users, Content, and Networks. Social Media+ Society, 1(2), 2056305115610141.

Larsson, A. O. (2015). Going viral? Comparing parties on social media during the 2014 Swedish election. Convergence: The International Journal of Research into New Media Technologies, doi:10.1177/1354856515577891

Leibold, J. (2010). More than a Category: Han Racial Nationalism on the Chinese Internet, The China Quarterly, 203: 539-559.

Liao, H.-T. (2009). Conflict and Consensus in the Chinese version of Wikipedia, IEEE Technology and Society Magazine, 28(2), pp. 49-56. 
Ling, R., Bjelland, J., Sundsøy, P. R., \& Campbell, S. W. (2014). Small circles: Mobile telephony and the cultivation of the private sphere. The Information Society, 30(4), 282-291.

Luhmann, N. (2000). The Reality of the Mass Media. Cambridge: Polity Press.

Mann, M. (2013). The Sources of Social Power, vol.4: Globalizations, 1945-2011. Cambridge: Cambridge University Press.

McCombs, M. (2013). Setting the agenda: The mass media and public opinion. London: John Wiley \& Sons.

Miller, D. et al. (2016). How the World Changed Social Media. London: UCL Press.

Napoli, P. \& Obar, J. (2015). The Emerging Mobile Internet Underclass: A Critique of Mobile Internet Access, The Information Society: An International Journal; 30:5, 323-334.

Neuman, Russell W. (2016). The Digital Difference: Media Technology and the Theory of Communication Effects. Cambridge MA: Harvard University Press.

Neuman, W. R., Guggenheim, L., Mo Jang, S. and Bae, S. Y. (2014). The Dynamics of Public Attention: Agenda-Setting Theory Meets Big Data. Journal of Communication, 64: 193-214.

Nielsen, R. K. (2012). Ground wars: Personalized communication in political campaigns. Princeton: Princeton University Press.

Nippert-Eng, C. E. (2010). Islands of privacy. Chicago: University of Chicago Press.

Norris, P.\& Inglehart, R. (2009). Cosmopolitan Communication: Cultural Diversity in a Globalized World. Cambridge: Cambridge University Press.

Qiu, J. (2009). Working-class network society: Communication technology and the information haveless in urban China. Cambridge MA: MIT Press

Pariser, E. (2011). The filter bubble: What the Internet is hiding from you. London: Penguin.

Prior, M. (2007). Post-Broadcast Democracy: How Media Choice Increases Inequality in Political Involvement and Polarizes Elections. Cambridge: Cambridge University Press.

Rainie, L., Smith, A., Schlozman, K. L., Brady, H., \& Verba, S. (2012). Social media and political engagement. Pew Internet \& American Life Project, http://www.pewinternet.org/2012/10/19/socialmedia-and-political-engagement/

Rieh, S. Y. (2004). On the Web at home: Information seeking and Web searching in the home environment. Journal of the American Society for Information Science and Technology, 55(8), 743753. 
Savolainen, R. (2008). Everyday Information Practices: A social phenomenological perspective. Lanham MD: Scarecrow Press.

Segev, E. \& Ahituv, N. (2010). Popular Searches in Google and Yahoo!: A "Digital Divide" in Information Uses? The Information Society 26 (1): 17-37.

Sen, A. (2009). The Idea of Justice. London: Allen Lane.

Stockmann, D. (forthcoming) Towards Area-Smart Data Science: Critical Questions for Working with Big Data from China. Available at SSRN 2718120.

Stockmann, D. (2013). Media commercialization and authoritarian rule in China. Cambridge: Cambridge University Press.

Thompson, J. (1995). The Media and Modernity: A Social Theory of the Media. Cambridge: Polity Press.

Waller, V. (2011). The search queries that took Australian Internet users to Wikipedia. Information Research, 16(2), June.

Waller, V. (2011). Not just information: Who searches for what on the search engine Google?. Journal of the American Society for Information Science and Technology, 62(4), 761-775.

Weibull, L. \& Wadbring, I. (2014). Mass Medier: Nya villkor för press, radio och tv i det digitala medialandskapet. Stockholm: Ekerlids.

Westlund, O. and Weibull, L. (2013), 'Generation, life course and news media use in Sweden 19862011', Northern Lights 11, pp. 147-173.

Whyte, M. (2010). Myth of the social volcano: Perceptions of inequality and distributive injustice in contemporary China. Stanford: Stanford University Press.

Yang, G. (2009). The power of the Internet in China: Citizen activism online. New York: Columbia University Press, 2009. 